\title{
The use of laser Doppler blood flow to assess the effect of acute administration of vitamin D on micro vascular endothelial function in people with diabetes
}

\author{
Jerrold Petrofsky, Faris Alshammari, Iman Akef Khowailed, Riya Lodha, Pooja Deshpande, Praveen Rajaram, \\ Mahendra Gaikwad, Vidhi Vadera
}

Department of Physical Therapy, School of Allied Health Professions, Loma Linda University, CA, USA

\begin{abstract}
Objective: To assess the effect of vitamin D administration on the skin blood flow response to occlusion and heat. Design: Cross-sectional study.

Methods: Twenty age matched subjects; 10 who had diabetes and 10 who were controls were administered 4,000 IU of vitamin D3 for 3 weeks at breakfast. The function of the endothelial cells was evaluated in 2 ways; first, the response to 4 minutes of vascular occlusion of the skin was measured with a laser Doppler flow meter. Second, the skin blood flow response to local heat at 42 degrees $\mathrm{C}$ for 6 minutes was examined.

Results: The results of the experiments showed that the blood flow response to heat was reduced after 3 weeks administration of vitamin $\mathrm{D}$ in the subjects with diabetes and in the control subjects $(p<0.05)$. The response to occlusion was not significantly different within each group before and after vitamin $\mathrm{D}$ administration, but the group with diabetes had a significantly lower blood flow response to occlusion than did the controls $(p<0.05)$.

Conclusions: Acute doses of vitamin D may impair nitric oxide production and reduce blood flow to tissue during stressors in people with diabetes.
\end{abstract}

Key Words: Diabetes, Endothelial cells, Inflammation, Vitamin D

\section{Introduction}

Endothelial dysfunction is common in the elderly and in people with diabetes [1-3]. Endothelial dysfunction is commonly caused by oxidative stress [2]. The most common causes of increased oxidative stress are high fat diets [1,4], ageing [5], diabetes [6-8] and smoking [9]. The damage to vascular endothelial cells impairs the ability of blood vessels to vasodilate. Since the vasoconstrictor pathway is largely undamaged, blood flow is restricted at rest and in response to stressors such as occlusion and heat $[1,2,10]$.

Coenzyme Q10 and vitamins A, C, and E reduce free radicals in the blood $[11,12]$. In the past 40 years an important vi- tamin that has been investigated is vitamin D [13]. This vitamin is actually a hormone that regulates the immune system, helps achieve calcium homeostasis, and down regulates angiotensin 2 [14,15]. Vitamin D is normally associated with sunlight exposure. Since societies across the world have shifted to a more industrial society, vitamin D has been found to be critically low in the blood of most populations due to less sunlight exposure; with diabetes it is even lower $[14,15]$.

Numerous studies have associated diabetes and heart disease with low concentrations of vitamin D in the blood [16]. Numerous studies have also studied the effects of 3-4 months of vitamin $\mathrm{D}$ administration on endothelial function

Received: 8 August, 2013 Revised: 27 November, 2013 Accepted: 29 November, 2013

Corresponding author: Jerrold Petrofsky

Department of Physical Therapy, School of Allied Health Professions, Loma Linda University, Loma Linda, California 92350, USA Tel: 1-909-558-7274 Fax: 1-909-558-0481 E-mail: jpetrofsky@llu.edu

(c) This is an Open-Access article distributed under the terms of the Creative Commons Attribution Non-Commercial License (http://creativecommons.org/licens es/by-nc/3.0) which permits unrestricted non-commercial use, distribution, and reproduction in any medium, provided the original work is properly cited.

Copyright $@ 2013$ Korean Academy of Physical Therapy Rehabilitation Science 
$[17,18]$. Endothelial function is usually assessed by the response of the brachial artery to 4 minutes of vascular occlusion. This elicits a vasodilation about 1 minute after the occlusion is released due to the activation of shear receptors $[19,20]$. These receptors mediate an increase in blood vessel diameter mediated by prostanoids and nitric oxide (NO). As such, the flow mediated dilation of large arteries is a good measure of endothelial function in these arteries. In people with diabetes, however, there are mixed results. Diabetes is associated with low vitamin D in the serum [20]. When people with diabetes were administered vitamin $\mathrm{D}$, some studies show improved flow mediated dilation and others do not [16]. One pathway altered by vitamin D is a direct effect on phosphotidyl inositol 3 kinase (PI3K) in endothelial cells [21]. This compound (PI3K) causes an increase in glucose transport into the cell [22]. It is of no surprise then that vitamin D has been shown in some studies to cause a reduction in blood glucose, especially in people with diabetes [23]. But PI3K has another role. It also causes the activation of endothelial NO synthetase, an enzyme that catalyzes the production of the blood vessel vasodilator NO from l-arginine $[2,24]$. It is of no surprise then, that the brachial artery response to vascular occlusion (flow mediated vasodilation) is increased in people who are on vitamin D supplements [13,25-28]. Complicating matters further, measurements are almost never made until 3 months after vitamin D administration; there are few studies on acute administration of vitamin D even in young people [16]. Finally, the response to arterial shear receptors may not be predictive of micro vascular function. In one study when the response to the occlusion was measured in the finger vs. the brachial artery in normal subjects, the response to occlusion in the arteries increased after vitamin $\mathrm{D}$ but the response of the finger did not [25]. Thus there may be very different effects of vitamin D in large arteries compared to small vascular beds. To understand micro vascular endothelial function, another stressor that has been studied is the response to heat.

With heat application, the initial phase is a rapid increase in skin blood flow (SBF) [29] and is mediated by sensory

Table 1. Demographics of the control group

$(\mathrm{N}=10)$

\begin{tabular}{lccrr}
\hline & $\begin{array}{c}\text { Age } \\
(\mathrm{yr})\end{array}$ & $\begin{array}{c}\text { Weight } \\
(\mathrm{kg})\end{array}$ & $\begin{array}{c}\text { Height } \\
(\mathrm{cm})\end{array}$ & BMI \\
\hline Mean & 53.2 & 77.4 & 166.4 & 28.0 \\
Standard deviation & 10.6 & 14.4 & 6.6 & 5.5 \\
\hline
\end{tabular}

BMI: body mass index. nerve neurotransmitters, such as calcitonin gene related peptide (CGRP) and substance P (SP) [30]. The second phase is a slow and prolonged increase in SBF, which is mediated by NO [30-35].

The local response to heat and occlusion provides an index of micro vascular function and is related to perfusion of organ vascular beds. The effects of vitamin $\mathrm{D}$ administration on people with diabetes have never been studied on micro vascular function. This was the purpose of the present investigation. This investigation used a laser Doppler flow meter to see if a more sensitive index of the effects of vitamin D could be shown in people with diabetes. Vitamin D was only given for 3 weeks to see if the blood flow response to local heat and occlusion would be sensitive enough to show an effect of vitamin D on people with diabetes.

\section{Methods}

\section{Subjects}

Twenty subjects participated in the experiments. Ten subjects were in each group. The demographics of the older control group and subjects with diabetes are listed in Tables 1 and 2 respectively. Subjects were not taking alpha blockers, beta blockers, alpha agonists or antagonists, or any other medication that would affect peripheral blood flow. They were not taking calcium channel blockers or any pain medications. All subjects were naïve for vitamin $\mathrm{D}$ at least for a month prior to the beginning of this study. No subjects were smokers. For the subjects with diabetes, the average $\mathrm{Hb}$ Alc was $7.3+/-0.7 \%$ and the average time since the diagnosis of diabetes was $7.1+/-1.9$ years. All methods and procedures were approved by the institutional review board of Loma Linda University. All subjects signed a statement of informed consent.

\section{Methods}

\section{Measurement of skin temperature}

Skin temperature was measured with a thermistor (SKT RX 202A) manufactured by BioPac systems (BioPac Inc.,

Table 2. Demographics of subjects with diabetes $\quad(\mathrm{N}=10)$

\begin{tabular}{lccrr}
\hline & $\begin{array}{c}\text { Age } \\
(\mathrm{yr})\end{array}$ & $\begin{array}{c}\text { Weight } \\
(\mathrm{kg})\end{array}$ & $\begin{array}{c}\text { Height } \\
(\mathrm{cm})\end{array}$ & BMI \\
\hline Mean & 59.7 & 85.2 & 167.1 & 30.6 \\
Standard deviation & 10.3 & 10.7 & 10.3 & 4.1 \\
\hline
\end{tabular}

BMI: body mass index. 
Goleta, CA, USA). The thermistor output was sensed by an SKT 100 thermistor amplifier (BioPac Inc.). The output, which was a voltage between 0 and 10 volts, was sampled with an analog to digital converter at a frequency of a 1,000 samples per second with a resolution of 24 bits with a BioPac MP150 (BioPac Inc.) analog to digital converter. The converted data was stored on a desktop computer using Acknowledge 3.9.1 software (BioPac Inc.) for future analysis. Data analysis was done over a 5 second period for mean temperature.

\section{Measurement of skin blood flow}

SBF was measured with either a Moor Laser Doppler Imager (LDF) or Moor Optical Fiber Flow Meter (VMS LDF2) (Moor Ltd., Oxford, England). The imager used a red laser beam $(632.8 \mathrm{~nm})$ at a power of $2.5 \mathrm{mw}$ to measure SBF using the Doppler effect. The laser, in this case, was used in a single point mode. After warming the laser for 20 minutes prior to use, the laser was focused on one area of the skin. By comparing the reflected light to the source light, the change in the frequency of the light and absorption of the light was used to calculate the red cell velocity and the red cell content in that area of the skin. The Moor Laser Doppler Imager measured blood flow through most of the dermal layer of the skin but did not penetrate the entire dermal layer. Blood flow was calculated in a unit called Flux based on the red cell concentration and red cell velocity with a stated accuracy of $+/-10 \%$. The LDF was used for the occlusion studies. For the heat studies, a single point fiber optic laser Doppler flow meter was used (VMS LDF2). This Moor instrument unit sampled a smaller area of the skin but was coupled to a heated probe as described below so that the assembly temperature was controlled. This flow meter provides less flow output due to the smaller surface area of the probe.

\section{Control of skin temperature}

Skin temperature was controlled by a Moor temperature controller (Moor VMS-heat, Moor Ltd.). This was a closed loop electric warmer where temperature is controlled to 0.1 degrees $\mathrm{C}$.

\section{Vitamins}

The dose of the vitamin used in the study was 4,000 IU of D3, taken daily (Kirkland Brand, Kirkland, WA, USA).

\section{Measurement of endothelial function}

Endothelial function was measured by the blood flow re- sponse to occlusion and heat.

\section{Occlusion}

The blood flow to the arm was occluded for 4 minutes by placing a pneumatic occlusion cuff on the upper arm above the elbow and inflating the cuff for 4 minutes at $200 \mathrm{mmHg}$. After the pressure was released, forearm blood flow was measured for 2 minutes to assess the reactivity of the blood vessels to occlusion and anoxia.

\section{Measurement of the response to heat}

The response of the skin to heat was measured by applying a heated probe to the skin for 6 minutes. The thermode was set at a temperature of 42 degrees centigrade. This warmed the skin and blood flow was recorded.

\section{Procedures}

The study design was a pre post non randomized controlled quasi experimental study. All subjects were administered vitamin D for 3 weeks in this study. Before and after this period of time, the entire group had their response to heat and occlusion measured.

\section{Data analysis}

Data analysis consisted of means and standard deviations and related and unrelated t tests. Mixed Factorial ANOVA was used to compare within and between groups. The level of significance was $p<0.05$.

\section{Results}

\section{Control subjects}

The blood flow response in the control subjects to heat is shown in Figure 1 before and after administration of vitamin D. There was no statistical difference comparing the blood flow in the skin pre and post vitamin $\mathrm{D}$ administration data from rest to 150 seconds after heat was applied $(p>0.05)$. However, from 150 to 30 seconds post heat, the blood flow in the skin were significantly lower after the administration of vitamin D for 3 weeks $(p<0.05)$. There was an average $27 \%$ reduction in blood flow with heat during the period from 150 seconds to 30 seconds post heat. Integrating the area under the 2 curves and subtracting the resting blood flow, there was 355.2 flux more blood flow pre vitamin D than post vitamin $\mathrm{D}$.

The blood flow response to occlusion is shown in Figure 2. The resting blood flow was greater here than in the heat series. 


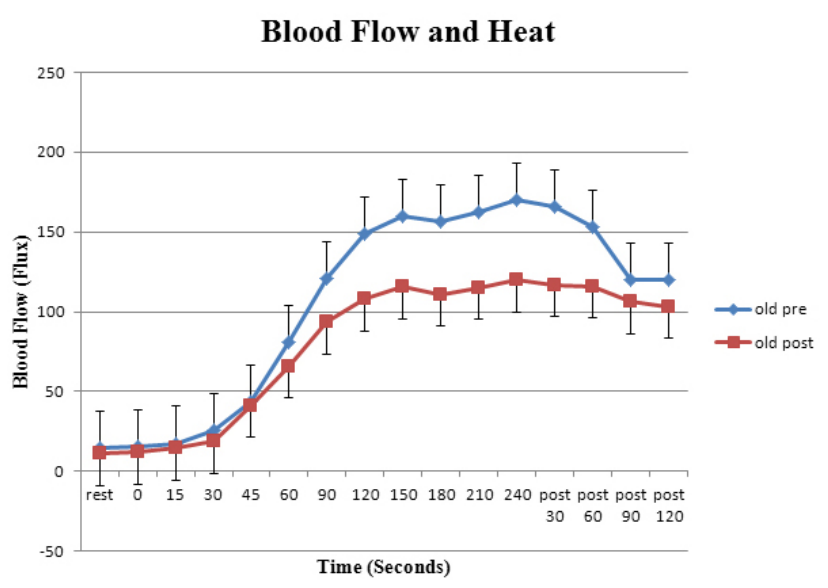

Figure 1. Illustrated here is the skin blood flow as the mean of 10 subjects plus or minus the standard deviation measured at rest and during 6 minutes of passive heating of the skin. Data is shown before (pre) and 3 weeks after (post) administration of vitamin D in 10 control subjects. The $\mathrm{x}$ axis shows the time for the resting blood flow and blood flow during 240 seconds of heat exposure and for 120 seconds after heat exposure.

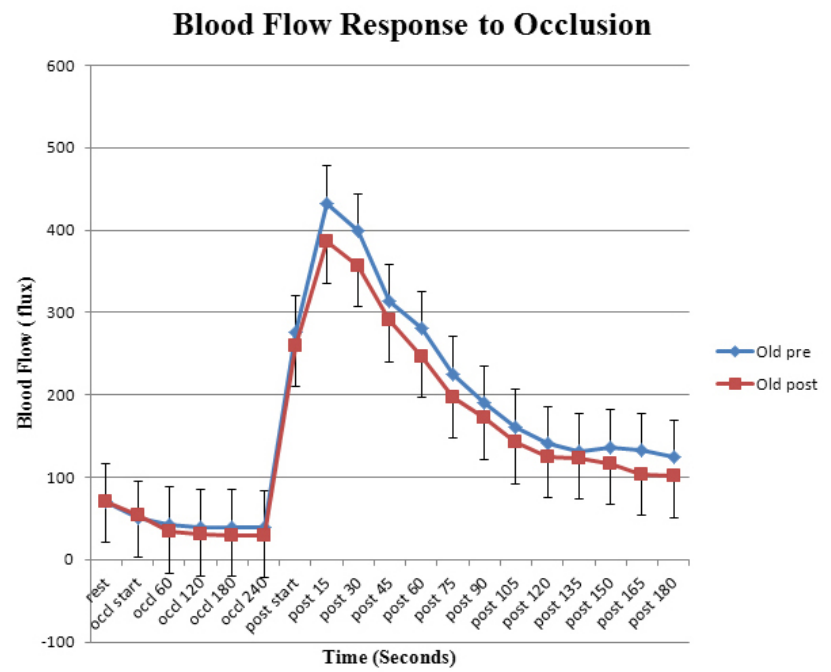

Figure 2. Illustrated here is the skin blood flow as the mean of 10 subjects plus or minus the standard deviation measured at rest and during and after 4 minutes of vascular occlusion. Data is shown before (pre) and 3 weeks after (post) administration of vitamin D in 10 control subjects. The $\mathrm{x}$ axis shows the time for the resting blood flow, blood flow during occlusion and for 180 seconds post occlusion.

This is due to the fact that a different imager was used for blood flow that sampled a larger area of the skin. As shown here, the blood flow response after occlusion was significantly higher than the blood flow after administration of vitamin $\mathrm{D}(p$ $<0.05$ ). Even the total flow as a result of occlusion (area un-

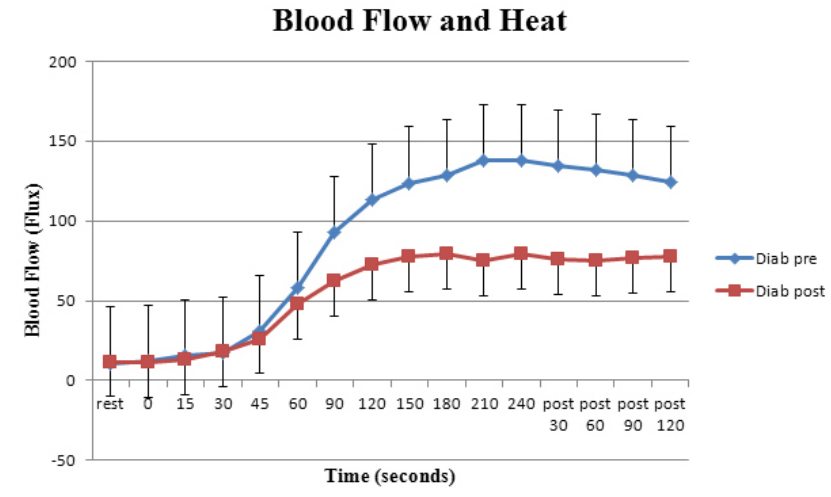

Figure 3. Illustrated here is the skin blood flow as the mean of 10 subjects plus or minus the standard deviation measured at rest and during 6 minutes of passive heating of the skin. Data is shown before (pre) and 3 weeks after (post) administration of vitamin D in 10 subjects with diabetes. The $\mathrm{x}$ axis shows the time for the resting blood flow and blood flow during 240 seconds of heat exposure and for 120 seconds after heat exposure.

\section{Blood Flow Response to Occlusion}

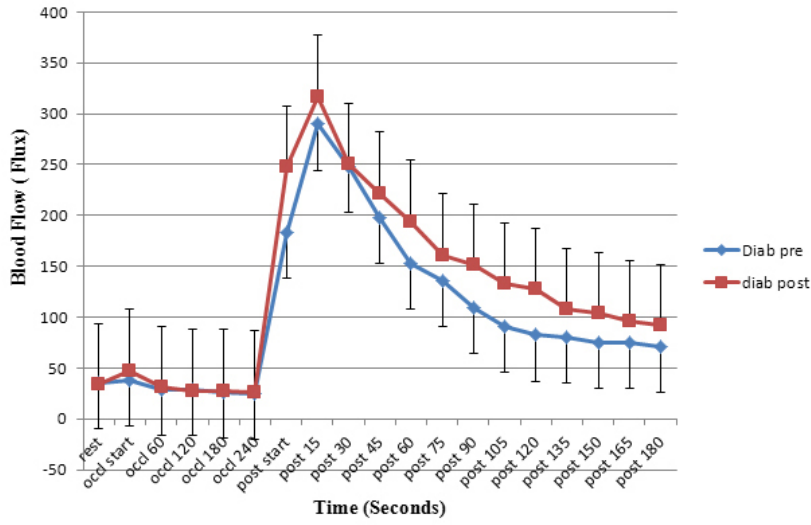

Figure 4. Illustrated here is the skin blood flow as the mean of 10 subjects plus or minus the standard deviation measured at rest and during and after 4 minutes of vascular occlusion. Data is shown before (pre) and 3 weeks after (post) administration of vitamin D in 10 subjects with diabetes. The $\mathrm{x}$ axis shows the time for the resting blood flow, blood flow during occlusion and for 180 seconds post occlusion.

der the flow curve) was significantly greater before than after administration of vitamin $\mathrm{D}(p<0.01)$.

\section{Subjects with diabetes}

The blood flow response to heat in the subjects with diabetes pre and post vitamin $\mathrm{D}$ administration is shown in Figures 3, 4. As seen here, the blood flow at rest and throughout the heat exposure was significantly lower than blood flow seen in age matched controls $(p<0.05)$. Further, the blood flow, as was seen in the controls, was lower post 
vitamin $\mathrm{D}$ than pre vitamin $\mathrm{D}$. As was the case for the control subjects, the first minute of heat exposure showed no difference in blood flow pre and post administration of vitamin D. But from that point to the end of heat exposure, the blood flows were reduced after administration of vitamin D.

The response to occlusion was less than that seen in the control subjects $(p<0.05)$ but there was no difference in the pre and post data seen here.

\section{Discussion}

Numerous studies have been conducted showing a link between the concentration of vitamin $\mathrm{D}$ in the blood and diabetes, heart disease and stroke [16]. The observation that vitamin D is inversely related to diseases such as MS and heart disease has caused the general belief that vitamin $\mathrm{D}$ is beneficial to people with cardiovascular disease [16]. This may be true, but in studies where vitamin $\mathrm{D}$ has been given at 4,000 IU per day for 3 months sometimes show a positive effect on vascular endothelial function and sometimes no effect at all. But some studies have been done with young people, some the elderly, many with people with known heart disease and some with people with diabetes. The results are mixed and it has been concluded that since many medications, smoking and chronic inflammation interfere with vitamin $\mathrm{D}$, that more carefully controlled studies need to be accomplished [16]. The present investigation was designed to study if the micro vascular response to occlusion and heat could detect the effect of an acute dose of vitamin D on endothelial function in people with diabetes. One problem in most studies of endothelial function is that large artery response to occlusion was the paradigm used to study vitamin D effects on blood vessels $[19,20,36]$. This measurement tests only 1 biochemical pathway that exists in endothelial cells. In the present investigation we took a more practical approach, the response to heat and local micro vascular response to occlusion, both of which are important in daily life for people with diabetes.

Measuring the local response to heat, as assessed with a laser Doppler flow meter, we found that, in the control subjects, the resting blood flow was not altered by 3 weeks administration of vitamin $\mathrm{D}$. This was also true during the first minute after the heat was applied to the skin in both the control and subjects with diabetes. While the subjects with diabetes had significantly less blood flow perfusing the skin during this first minute, this is not surprising since previous studies show impairment in the ability of the skin to response to heat in people with diabetes due to endothelial cell dysfunction [10,37-40]. The blood flow in the first minute after application of the heat in either group of subjects comparing the pre and post vitamin $\mathrm{D}$ administration data shows no effect of vitamin $D$. The initial blood flow increase with heat is mediated by CGRP and SP $[29,30]$ was unaltered by acute administration of vitamin D. But the sustained response of blood flow to heat is mediated largely by NO [30,31]. In younger individuals there is a contribution of prostacyclin [41,42], but in older people this pathway is not very active and NO is the predominant pathway. Therefore for some reason, acute administration of vitamin $\mathrm{D}$ has altered the NO response to heat. There is evidence that vitamin $\mathrm{D}$ increases calcium influx in arteries and increases their stiffness [43]. But if this were the case, then the resting blood flow and that during the first minute would also be altered. Therefore, this was not the case. Generally, on large studies where vitamin $\mathrm{D}$ is given for months, there is an improvement in most people in flow mediated dilation of the brachial artery [44]. This is also mediated by NO. But here the effect is opposite. One problem maybe that of relative related rates in the time sequence for when vitamin D alters each of the different pathways it affects. Vitamin D receptors modulate multiple pathways in the body. One of these is calcium metabolism $[45,46]$. This is a fast responding pathway and even a single dose of vitamin D can alter bone density [46]. But the response is variable. Due to polymorphisms in the vitamin D receptor, some people response strongly and others do not [47]. The large standard deviations here in the blood flow response to heat attest to these differences. The second effect of vitamin $\mathrm{D}$ is on the renin-angiotensin pathway. A third effect is on reducing blood carried free radicals [16]. This later immune system response takes time to reverse free radical damage and as such would take months of administration. Further, since vitamin D is stored in body fat. It can take months to build the blood concentration high enough to modulate the immune system.

No previous study has examined in the elderly or people with diabetes the effect of a 3 week course of vitamin D. A logical conclusion is that future studies need to monitor weekly effects in relation to the blood concentration of vita$\min \mathrm{D}$ to understand the related rates of these pathways. The response to occlusion in the diabetic group was even reduced but the change was small. Perhaps 1 week after administration the reduction may have been more significant. These are questions that need to be answered on vitamin D by monitoring its effect on a weekly basis to see the rates of 
different pathways in the future. Another limitation of the study was that we did not examine brachial artery occlusion mediated vasodilation. Since brachial flow mediated dilation is mediate by $\mathrm{NO}$ as is the prolonged response of blood flow to heat, it can be predicted that this pathway would also show a reduction at 3 weeks after vitamin $\mathrm{D}$ administration. The local response to occlusion is not mediated by NO but is a response to anoxia mediated by neither NO nor prostaglandins [48]. A good study would use all three tools to assess vascular damage in relation to vitamin $\mathrm{D}$ in people with diabetes since multiple blood vessel controlling pathways could be evaluated.

There are some limitations of the study. First, other vitamins such as Coq10 and E were not controlled. Second, the study should be repeated with more subjects and for a longer period of time to see if the acute effect of $\mathrm{D}$ administration is altered with chronic use.

\section{References}

1. Yim J, Petrofsky J, Berk L, Daher N, Lohman E. Differences in endothelial function between Korean-Asians and Caucasians. Med Sci Monit 2012;18:CR337-43.

2. Petrofsky J, Berk L, Al-Nakhli H. The influence of autonomic dysfunction associated with aging and type 2 diabetes on daily life activities. Exp Diabetes Res 2012;2012:657103.

3. Petrofsky JS, Alshahmmari F, Lee H, Hamdan A, Yim JE, Shetye $\mathrm{G}$, et al. Reduced endothelial function in the skin in Southeast Asians compared to Caucasians. Med Sci Monit 2012;18:CR1-8.

4. Bui C, Petrofsky J, Berk L, Shavlik D, Remigio W, Montgomery $\mathrm{S}$. Acute effect of a single high-fat meal on forearm blood flow, blood pressure and heart rate in healthy male Asians and Caucasians: a pilot study. Southeast Asian J Trop Med Public Health 2010;41:490-500.

5. Forbes SC, Little JP, Candow DG. Exercise and nutritional interventions for improving aging muscle health. Endocrine 2012; 42:29-38.

6. Hegde SV, Adhikari P, Kotian S, Pinto VJ, D'Souza S, D'Souza V. Effect of 3-month yoga on oxidative stress in type 2 diabetes with or without complications: a controlled clinical trial. Diabetes Care 2011;34:2208-10.

7. Hegde KR, Varma SD. Combination of glycemic and oxidative stress in lens: implications in augmentation of cataract formation in diabetes. Free Radic Res 200;39:513-7.

8. Hegde HR. Diabetes mellitus, acquired immune deficiency syndrome and tuberculosis. Med Hypotheses 2005;64:1065.

9. Vande Loock K, Ciardelli R, Decordier I, Plas G, Haumont D, Kirsch-Volders M. Preterm newborns show slower repair of oxidative damage and paternal smoking associated DNA damage. Mutagenesis 2012;27:573-80.

10. Petrofsky JS. The effect of type-2-diabetes-related vascular endothelial dysfunction on skin physiology and activities of daily living. J Diabetes Sci Technol 2011;5:657-67.
11. Landberg R, Naidoo N, van Dam RM. Diet and endothelial function: from individual components to dietary patterns. Curr Opin Lipidol 2012;23:147-55.

12. Hansen L, Skeie G, Landberg R, Lund E, Palmqvist R, Johansson $\mathrm{I}$, et al. Intake of dietary fiber, especially from cereal foods, is associated with lower incidence of colon cancer in the HELGA cohort. Int J Cancer 2012;131:469-78.

13. Caprio M, Mammi C, Rosano GM. Vitamin D: a novel player in endothelial function and dysfunction. Arch Med Sci 2012;8:4-5.

14. Zittermann A. Vitamin D in preventive medicine: are we ignoring the evidence? Br J Nutr 2003;89:552-72.

15. Zittermann A, Schleithoff SS, Tenderich G, Berthold HK, Körfer R, Stehle P. Low vitamin D status: a contributing factor in the pathogenesis of congestive heart failure? J Am Coll Cardiol 2003;41:105-12.

16. Beveridge LA, Witham MD. Vitamin D and the cardiovascular system. Osteoporos Int 2013;24:2167-80.

17. Molinari C, Uberti F, Grossini E, Vacca G, Carda S, Invernizzi M, et al. 1 $\alpha, 25$-dihydroxycholecalciferol induces nitric oxide production in cultured endothelial cells. Cell Physiol Biochem 2011;27:661-8.

18. Cardus A, Panizo S, Encinas M, Dolcet X, Gallego C, Aldea M, et al. 1,25-dihydroxyvitamin D3 regulates VEGF production through a vitamin D response element in the VEGF promoter. Atherosclerosis 2009;204:85-9.

19. Witham MD, Dove FJ, Khan F, Lang CC, Belch JJ, Struthers AD. Effects of Vitamin D supplementation on markers of vascular function after myocardial infarction--a randomised controlled trial. Int J Cardiol 2013;167:745-9.

20. Muscogiuri G, Sorice GP, Ajjan R, Mezza T, Pilz S, Prioletta A, et al. Can vitamin $\mathrm{D}$ deficiency cause diabetes and cardiovascular diseases? Present evidence and future perspectives. Nutr Metab Cardiovasc Dis 2012;22:81-7.

21. Wang HJ, Cao JP, Yu JK, Zhang LC, Jiang ZJ, Gao DS. Calbindin-D28K expression induced by glial cell line-derived neurotrophic factor in substantia nigra neurons dependent on PI3K/Akt/NF-kappaB signaling pathway. Eur J Pharmacol 2008;595:7-12.

22. Xu TJ, Liu Y, Yuan B. Effect of insulin in combination with selenium on Irs/PI3K-mediated GLUT4 expression in cardiac muscle of diabetic rats. Eur Rev Med Pharmacol Sci 2011;15:145260.

23. Takiishi T, Gysemans C, Bouillon R, Mathieu C. Vitamin D and diabetes. Rheum Dis Clin North Am 2012;38:179-206.

24. Petrofsky J, Alshahmmari F, Yim JE, Hamdan A, Lee H, Neupane S, et al. The interrealtionship between locally applied heat, ageing and skin blood flow on heat transfer into and from the skin. J Med Eng Technol 2011;35:262-74.

25. Duprez D, de Buyzere M, de Backer T, Clement D. Relationship between vitamin D3 and the peripheral circulation in moderate arterial primary hypertension. Blood Press 1994;3:389-93.

26. Zawada ET Jr, TerWee JA, McClung DE. Systemic and renal vascular responses to dietary calcium and vitamin D. Hypertension 1986;8:975-82.

27. Holick MF. Vitamin D deficiency. N Engl J Med 2007;357: 266-81.

28. Holick MF, Chen TC, Lu Z, Sauter E. Vitamin D and skin physiology: a D-lightful story. J Bone Miner Res 2007;22(Suppl 
2):V28-33.

29. Charkoudian N, Eisenach JH, Atkinson JL, Fealey RD, Joyner MJ. Effects of chronic sympathectomy on locally mediated cutaneous vasodilation in humans. J Appl Physiol (1985) 2002;92: 685-90.

30. Minson CT, Berry LT, Joyner MJ. Nitric oxide and neurally mediated regulation of skin blood flow during local heating. J Appl Physiol (1985) 2001;91:1619-26.

31. Kellogg DL Jr, Liu Y, Kosiba IF, O'Donnell D. Role of nitric oxide in the vascular effects of local warming of the skin in humans. J Appl Physiol (1985) 1999;86:1185-90.

32. Minson JB, Llewellyn-Smith IJ, Arnolda LF. Neuropeptide Y mRNA expression in interneurons in rat spinal cord. Auton Neurosci 2001;93:14-20.

33. Petrofsky J, Bains G, Prowse M, Gunda S, Berk L, Raju C, et al. Dry heat, moist heat and body fat: are heating modalities really effective in people who are overweight? J Med Eng Technol 2009;33:361-9.

34. Petrofsky J, Goraksh N, Alshammari F, Mohanan M, Soni J, Trivedi M, et al. The ability of the skin to absorb heat; the effect of repeated exposure and age. Med Sci Monit 2011;17:CR1-8.

35. Petrofsky JS, Laymon M. Heat transfer to deep tissue: the effect of body fat and heating modality. J Med Eng Technol 2009;33: $337-48$.

36. Witham MD. Should we be giving enhanced vitamin $D$ intakes to all? J R Coll Physicians Edinb 2012;42:189.

37. Petrofsky JS. Resting blood flow in the skin: does it exist, and what is the influence of temperature, aging, and diabetes? J Diabetes Sci Technol 2012;6:674-85.

38. Petrofsky J, Paluso D, Anderson D, Swan K, Alshammari F, Katrak V, et al. The ability of different areas of the skin to absorb heat from a locally applied heat source: the impact of diabetes. Diabetes Technol Ther 2011;13:365-72.

39. McLellan K, Petrofsky JS, Zimmerman G, Prowse M, Bains G, Lee $\mathrm{S}$. Multiple stressors and the response of vascular endothelial cells: the effect of aging and diabetes. Diabetes Technol Ther 2009;11:73-9.
40. Petrofsky JS, McLellan K, Bains GS, Prowse M, Ethiraju G, Lee $\mathrm{S}$, et al. Skin heat dissipation: the influence of diabetes, skin thickness, and subcutaneous fat thickness. Diabetes Technol Ther 2008;10:487-93.

41. Hellsten Y, Nyberg M, Jensen LG, Mortensen SP. Vasodilator interactions in skeletal muscle blood flow regulation. J Physiol 2012;590:6297-305.

42. Nyberg M, Jensen LG, Thaning P, Hellsten Y, Mortensen SP. Role of nitric oxide and prostanoids in the regulation of leg blood flow and blood pressure in humans with essential hypertension: effect of high-intensity aerobic training. J Physiol 2012;590: 1481-94.

43. Duprez D, De Buyzere M, De Backer T, Clement D. Relationship between vitamin $\mathrm{D}$ and the regional blood flow and vascular resistance in moderate arterial hypertension. J Hypertens Suppl 1993; 11:S304-5

44. Tarcin O, Yavuz DG, Ozben B, Telli A, Ogunc AV, Yuksel M, et al. Effect of vitamin D deficiency and replacement on endothelial function in asymptomatic subjects. J Clin Endocrinol Metab 2009;94:4023-30.

45. Rossini M, Adami S, Viapiana O, Fracassi E, Idolazzi L, Povino $\mathrm{MR}$, et al. Dose-dependent short-term effects of single high doses of oral vitamin $\mathrm{D}(3)$ on bone turnover markers. Calcif Tissue Int 2012;91:365-9.

46. Rossini M, Gatti D, Viapiana O, Fracassi E, Idolazzi L, Zanoni S, et al. Short-term effects on bone turnover markers of a single high dose of oral vitamin $\mathrm{D}_{3}$. J Clin Endocrinol Metab 2012;97: E622-6.

47. Arabi A, Zahed L, Mahfoud Z, El-Onsi L, Nabulsi M, Maalouf J, et al. Vitamin D receptor gene polymorphisms modulate the skeletal response to vitamin D supplementation in healthy girls. Bone 2009;45:1091-7.

48. Lopez MG, Silva BM, Joyner MJ, Casey DP. Roles of nitric oxide and prostaglandins in the hyperemic response to a maximal metabolic stimulus: redundancy prevails. Eur J Appl Physiol 2013;113:1449-56. 